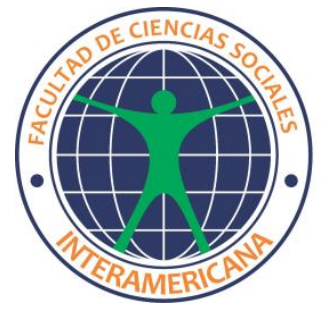

INSTITUTO SUPERIOR INTERAMERICANO DE CIENCIAS SOCIALES

FACULTAD INTERAMERICANA DE CIENCIAS SOCIALES MESTRADO EM CIÊNCIAS DA EDUCAÇÃO

EVERTON CARLOS FARIAS GAIA

A IMPORTÂNCIA DA HISTÓRIA LOCAL NO ENSINO FUNDAMENTAL 2 EM ESCOLAS DE TUCURUÍ - PA 


\section{EVERTON CARLOS FARIAS GAIA}

\section{A IMPORTÂNCIA DA HISTÓRIA LOCAL NO ENSINO FUNDAMENTAL 2 EM ESCOLAS DE TUCURUÍ - PA}

Artigo científico apresentado ao Programa de Postgrado da Facultad Interamericana de Ciencias Sociales- FICS, como requisito para obtenção de nota do Seminário: Perspectivas atuais de Investigação em Ciências da Educação no Curso de Doutorado em Ciências da Educação.

Orientador: Prof ${ }^{\circ}$. Doutor Mílvio da Silva Ribeiro

TUCURUÍ - PA 


\section{EVERTON CARLOS FARIAS GAIA}

\section{A IMPORTÂNCIA DA HISTÓRIA LOCAL NO ENSINO FUNDAMENTAL 2 EM ESCOLAS DE TUCURUÍ - PA}

Artigo científico apresentado ao Programa de Postgrado da Facultad Interamericana de Ciencias Sociales- FICS, como requisito para obtenção de nota do Seminário: Perspectivas atuais de Investigação em Ciências da Educação no Curso de Doutorado em Ciências da Educação.

Orientador: $\operatorname{Prof}^{\circ}$. Doutor Mílvio da Silva Ribeiro 


\title{
A IMPORTÂNCIA DA HISTÓRIA LOCAL NO ENSINO FUNDAMENTAL 2 EM ESCOLAS DE TUCURUÍ - PA
}

\author{
Everton Carlos Farias Gaia ${ }^{1}$
}

\begin{abstract}
RESUMO
A História local possibilita a compreensão do entorno do aluno, identificando passado e presente nos vários espaços de convivência. Essa temática permite que o professor parta das histórias individuais e dos grupos, inserindo o aluno em contextos mais amplos. Nesse sentido, a proposta visa discutir e analisar a relevância de se abordar a história local nas escolas de Ensino Fundamental 2 ( 6 - ao 9o ano), destacando para os estudantes a importância de conhecer as particularidades da sua região e da sua comunidade, que falam, de certo modo, da sua história e dos seus antepassados A partir dos conceitos, a pesquisa versará sobre a importância da importância da história local e sua aplicabilidade no ensino, visando a melhoria da prática docente nas escolas de Ensino Fundamental 2 ( $6^{\circ}$ ao $9^{\circ}$ ano), destacando a importância de se conhecer as particularidades da região e da comunidade em que se vive, falando-se da sua história e dos seus antepassados, para que se possa aprimorar as informações obtidas em bancos de dados locais e nacionais para demonstrar peculiaridade, dando possibilidades a realizações de pesquisas que trazem subsidio de intervenção nas práticas de ensino dos profissionais da licenciatura em história.
\end{abstract}

PALAVRAS-CHAVE: história local, aluno, região, particularidades, práticas de ensino.

\section{RESUMEN}

La historia local permite comprender el entorno del alumno, identificando pasado y presente en los distintos espacios de vida. Este tema permite al docente partir de historias individuales y grupales, insertando al alumno en contextos más amplios. En este sentido, la propuesta tiene como objetivo discutir y analizar la relevancia de abordar la historia local en las escuelas primarias $2\left(6^{\circ}\right.$ a $9^{\circ}$ grado), destacando para los estudiantes la importancia de conocer las particularidades de su región y su comunidad, quienes hablan, de una manera, de su historia y sus antepasados A partir de los conceptos, la investigación abordará la importancia de la importancia de la historia local y su aplicabilidad en la docencia, con el objetivo de mejorar la práctica docente en las Escuelas Primarias $2\left(6^{\circ}\right.$ a $9^{\circ}$ año), destacando la importancia de conocer las particularidades de la región y la comunidad en la que viven, hablar de su historia y sus antepasados, para que la información obtenida en las bases de datos locales y nacionales pueda ser mejorada para demostrar peculiaridad, dando posibilidades a investigaciones que traigan subsidio para la intervención en las prácticas docentes de los profesionales de la licenciatura en historia.

PALABRAS CLAVE: historia local, alumno, región, particularidades, práctica docente.

\footnotetext{
${ }^{1}$ Mestrando em Ciências da Educação da FICS - Faculdad Interamericana de Ciências Sociales
} 


\section{INTRODUÇÃO}

A formação de um estudante deve conter sua história e a história da sua região, que fazem toda diferença no seu futuro e na sua qualificação profissional, com vistas a prepará-lo de maneira mais consciente para exercer o seu papel na sociedade, a partir do entendimento de que a cultura e a memória forma pessoas mais realistas e preparadas para exercitar a sua cidadania.

História é um termo polissêmico. Se encontrarmos essa palavra isolada, não saberemos qual significado Ihe atribuir. Quando nos referirmos ao termo "história", podemos estar nos referindo à história acontecimento, ou seja, ao que foi vivido, ao passado. Por outro lado, podemos também estar nos referindo ao resultado final do trabalho do historiador, ou seja, à História conhecimento. (FAGUNDES; ANDRADE, 2017, p. 24).

Essa abordagem regional, quando bem explorada, quebra os paradigmas da educação e aproxima a escola da realidade do educando, bem como da realidade em que a escola está inserida, proporcionando uma aprendizagem mais real e mais afetiva.

O ensino da história na maioria das escolas aborda apenas as questões nacionais, de grande impacto, deixando de lado detalhes regionais que fazem toda diferença, inclusive no entendimento do aluno acerca das suas raízes e da sua origem. Isso desmotiva esse estudante e torna o seu processo educacional mais frio e mecânico. Isso mostra que a educação que privilegia apenas as histórias - muitas vezes fantasiosas apresentadas nos livros não é uma proposta altamente eficiente, pois priva os estudantes de terem contato com detalhes importantes da construção da sua comunidade, do posicionamento dos seus antepassados frente a esse momento.

Nossa pesquisa se fundamenta ao acreditar que o aprendizado histórico em constante diálogo com as diversas áreas e com as experiências próximas e locais do aluno, se solidifica e permite que ele, enquanto cidadão se perceba um sujeito histórico do espaço, do tempo e da sua comunidade.

Parte-se da hipótese que o ensino de história, ao privilegiar também a história local, poderá ajudar o aluno na compreensão do espaço, e aproximando-o, enquanto cidadão, do fato histórico, permitindo uma compreensão maior das diferenças existentes entre as diferentes regiões, podendo assim tornar a compreensão, e, consequentemente, o desenvolvimento do raciocínio a apropriação da realidade concreta mais eficaz. 


\section{2- A HISTÓRIA LOCAL NA PRÁTICA DE ENSINO.}

A prática do diálogo entre a didática do ensino de História e o conhecimento científico nos mostra a importância social dos estudos históricos na formação do aluno, demonstrando e consolidando a possibilidade de estudo e atividade que venha a valorizar o protagonismo intelectual do aluno, através do desenvolvimento e envolvimento em atividades que favoreçam a própria autonomia para destacar o aprendizado.

Nesse contexto, a prática do estudo de história vem para efetivar um papel importante, pois na medida em que une a pesquisa e reflexão do intrínseco jogo de relações construído pela sociedade, além da relação contínua que acontece diariamente entre indivíduo, grupo e o mundo social.

Assim, o ensino de História poderá fazer escolha pedagógica capaz de fazer com que o aluno reflita sobre seus valores e suas práticas do dia a dia, relacionando-as com a problemática histórica que está presente em seu grupo de convivência, na localidade em que vive, na região, ou ainda na sociedade nacional e mundial. Essa espécie de construção de noções vem para alterar a maneira como o aluno compreende os elementos do mundo e o leva a compreender as relações que esses elementos estabelecem entre si, pois o ensino de História vem para lhe possibilitar construir noções, trazendo alterações na sua forma de percepção em relação a si mesmo, compreender os outros indivíduos, as relações sociais e a própria História. Tem sido recorrente em propostas curriculares e em algumas produções didáticas introduzir a "História do Cotidiano", opção esta que não é uma conceptualização recente.

A associação entre cotidiano e a história de vida dos alunos possibilita contextualizar essa vivência individual a uma história tida e compreendida como coletiva. Os autores que se ocupam da História do Cotidiano, mesmo com posturas distintas em seus fundamentos teóricos, procuram recuperar as relações mais complexas entre os diversos grupos socais, estabelecendo conexões entre conflitos diários que se baseiam em um aspecto de política contestatória e identificar as lutas de resistência a mudanças, o apego e nostalgia a tradições. 


\section{3 - O ENSINO REGIONALISTA}

O ensino da história local nas escolas associa a pesquisa e a reflexão acerca de um tema que faz parte do cotidiano de todas as pessoas e que é tão esquecido em detrimento da história nacional, que deixa de lado pequenos detalhes e contribuições que fizeram toda a diferença na construção do Brasil de hoje.

Nesse ínterim, uma abordagem mais regionalista do ensino da História nas escolas de Ensino Fundamental levanta uma reflexão junto aos alunos, fazendo-os entender melhor o mundo a partir dos seus valores e da sua realidade e realizando uma analogia entre os problemas percebidos e vividos e as soluções que podem ser apresentadas diante das situações históricas e repetitivas que precisam e podem ser resolvidas, desde que o conhecimento seja bem aplicado e explorado.

A trajetória dos estudos sobre a abordagem histórica local e regional perpassa pelo processo de construção das novas concepções históricas, fruto dos questionamentos e das discussões em torno da historiografia e da tradicional concepção iluminista, até então, de uma visão positivista da História como progresso da humanidade (SILVA, 2009:182).

Dessa forma, o ressurgimento e a ressignificação da história local se deu no processo das revoluções historiográficas do século $X X$ como também, no diálogo interdisciplinar com as ciências sociais e, em especial, com a geografia, que trouxe como contribuição e solidificação para a discussão histórica local os conceitos de espaço, território, região, paisagem, dentre outros. Esta aproximação com a geografia, segundo José D’Assunção Barros deu-se, a priori, na ampliação da discussão conceitual da própria História como ciência que estuda o homem no passado.

A partir de agora, a história como "estudo do homem no tempo e no espaço" possibilita um alargamento da percepção de que os estudos dos homens, das sociedades, dos fatos, das culturas, estão inseridos em contextos e em espaços, quer sejam estes, físicos, geográficos ou políticos (BARROS, 2005:96-97).

Sendo assim, a definição conceitual de história local como a que faz referência aos estudos de pequenos e localizados espaços, aquela clássica afirmação de Pierre Goubert que diz respeito a uma ou poucas aldeias, às pequenas e médias cidades ou à determinadas áreas geográficas não tão extensas como algumas províncias, é 
frequentemente utilizada para iniciar os trabalhos e pesquisas que concentram seus esforços em desenvolver estudos sobre bairros, pequenos municípios e vilarejos.

\section{4 - AS VANTAGENS DO ENSINO DA HISTÓRIA LOCAL}

Goubert afirma que nas últimas décadas do século XX esta nova abordagem sobre a história local "tornou-se possível" porque alguns "historiadores que, não tendo em geral nascido nas regiões estudadas, e não expressando por essa devoção filial, trouxeram novamente à moda o retorno a arquivos inexplorados de certa região e de um dado período" (GOUBERT, 1998:70-73).

A educação deve desenvolver nos alunos conceitos de temporalidade, espacialidade, identidade, dentre outros, no âmbito da História Local, já que a partir do local é possível identificar e estudar diversos aspectos sociais nos mais variados campos da ação humana. "Os estudos da História Local conduzem aos estudos dos diferentes modos de viver no presente e em outros tempos, que existem ou que existiram no mesmo espaço" (BRASIL, 1997, p. 52). Estudando o local, os alunos têm oportunidade de perceber mudanças e permanências, descobrindo entre suas ações cotidianas a presença de elementos culturais vivenciados por gerações anteriores.

A História Local é potencialmente apropriada para despertar nas crianças o gosto por conhecer as realizações humanas produzidas no bailar dos tempos, retirando da disciplina História a sisudez das datas e acontecimentos pontuais e lineares.

Considera-se que a História Local, assunto a ser tratado na escolarização, diz respeito a uma espacialidade determinada que expressa particularidades articuladas ao todo social, pois, vive-se uma época que aponta para a supressão de barreiras culturais entre sociedades, deliberando uma interdependência entre o local e o global. Assim, é um campo fértil para estudos históricos, articulando aspectos econômicos, sociais e políticos determinados espacialmente, porém, imbricados a uma realidade mais ampla. Hoje a História Local aparece como reveladora de uma História mais geral, um 'local' privilegiado no sentido de levar os alunos a sentirem-se sujeitos da História a partir de suas próprias singularidades.

Em suma, os alunos devem ter condições de aprender conteúdos científicos com autonomia e efetiva interação com os saberes. Com isso, amplia-se o debate quanto a uma escola promotora de estudos e atividades que favoreçam aprendizagens significativas, que concorram para a formação global dos educandos. A História é uma 
das disciplinas que desempenha papel preponderante nesta formação, pois tem como base de seus conteúdos, reflexões pertinentes as relações que indivíduos e grupos estabelecem com os conhecimentos produzidos ao longo da trajetória humana.

\section{CONSIDERAÇÕES FINAIS}

O artigo buscou enfatizar que o ensino da história local é necessário para a própria construção da identidade de cada cidadão, através do seu conhecimento, de suas tradições, de sua vida. Dessa forma, não adianta pensarmos na construção psicossocial do ser humano, sem atentarmos que somos seres que estamos em constante interação com o meio que nos rodeia.

Assim sendo, a pesquisa procurou demonstrar que somos história, e fazemos história continuamente. Então, a história local, que está mais próxima de nós, nos convida a refletir mais sobre o que somos, de onde viemos e para onde queremos ir. Sem falar que torna o ensino e seus complicados procedimentos metodológicos, em uma atividade mais simples, de fácil entendimento, uma vez que estará se tratando da história local, fatos que os discentes tem mais aproximação.

Nesse sentido, a melhoria do acervo das bibliotecas escolares, no que tange à história local, poderia servir de base para elaboração de material próprio pelos educadores, como a obra "Tucuruí - Uma análise da visão do Estado sobre o campesinato", de Sônia Barbosa Magalhães, pesquisadora, doutoranda em Antropologia Social, a obra A memória em disputa: as lutas dos atingidos pela UHE de Tucuruí, de Leandro César Juárez Liberatori, e Usina Hidrelétrica de Tucuruí (Brasil), Estudos de Caso da Comissão Mundial de Barragens, dentre outros.

Conclui-se com esse estudo que há de se proporcionar aos educadores, mais cursos de formação, para que os mesmos possam ter a sua disposição mais metodologias e assim, renovem continuamente a sua pedagogia, introduzindo e massificando o uso da história local. Uma adequação possível também seria nos livros didáticos fornecidos pelo Governo Federal, que, de uma forma mais regionalizada, poderiam ter maior eficácia dentro do processo educacional, trazendo a história local de cada região, contribuindo significativamente para a melhoria dos processos de ensinoaprendizagem, e acima de tudo, atuando na construção de cidadãos. 


\section{REFERÊNCIAS}

BRASIL. Ministério da Educação e Cultura. Parâmetros curriculares da educação. Brasília: MEC, 1997. Disponível em <http://www.mec.gov.br> Acesso em 22 novembro 2020.

CASTRO, Antônio Alberto Q.; CARDOSO, João Marques. História da cidade de Tucuruí. 2012. Disponível em <http://cidadedetucurui.com/INICIO/A_CIDADE/HIST\%C3\%93RIA/AHISTORIA.htm> Acesso em 22 novembro 2020.

BARROS, José. A escrita da história. 2.ed. Rio de Janeiro: Forense Universitária, 2002.

ELETRONORTE. Tucuruí. 2017. Disponível em

<http://www.eletronorte.gov.br/opencms/opencms/aEmpresa/regionais/tucurui/> Acesso em 22 novembro 2020.

FAGUNDES, José Evangelista; ANDRADE, Joel Carlos de Souza. Pensando a história: noções introdutórias. Natal, RN: Editora da UFRN, 2017.

GIL, Antônio Carlos. Técnicas de pesquisa em economia e elaboração de monografias. 4.ed. São Paulo: Atlas, 2002.

GONÇALVES, Maria de Almeida. História local: o recohecimento da identidade pelo caminho da insignificância. In: MONTEIRO, Ana Maria. Et all (org.). Ensino de história: sujeitos, saberes e práticas. Rio de Janeiro: MauadX Faperj, 2007.

GOUBERT, P. História local. Revista Arrabaldes: por uma história democrática, Rio de Janeiro, n. 1, maio/ago. 1988.

GUIMARÃES, S. Didática e prática de ensino de história. 12.ed. Campinas-SP: Papirus, 2011.

MAGALHÃES, Sônia Barbosa. Tucuruí - uma análise da visão do Estado sobre o campesinato. 2002

SILVA, Amadeu. Razão histórica: teoria da história: fundamentos da ciência Histórica. Brasília: UnB, 2019.

SCHMIDT, Maria auxiliadora; CAINELLI, Marlene. Ensinar História. São Paulo: Scipione, 2004.

USINA HIDRELÉTRICA DE TUCURUÍ (BRASIL) Estudos de Caso da Comissão Mundial de Barragens. 2010.

VERGARA, Sylvia Constant. Projetos e relatórios de pesquisa em administração. 5.ed. São Paulo: Atlas, 2014. 